\title{
Evaluating the role of feedback regulation in recognition processing
}

\author{
Tsvi Achler \\ From Nineteenth Annual Computational Neuroscience Meeting: CNS*2010 \\ San Antonio, TX, USA. 24-30 July 2010
}

How the brain is able to perform recognition, especially of simultaneous patterns, is not clear. There are enormous amounts top-down feedback found within sensory processing regions of the brain which play a central role. However, these types of connections generate nonlinear dynamics, which are difficult to analyze mathematically.

Simplifying the analysis, it is hypothesized that the purpose of feedback is to regulate or conserve of information. The computational basis of conservation of information is: that each input should only pass a fixed amount of information than to the next layer. If an input activates the output layer too vigorously, its information is ambiguous (because may outputs are using it) and it is quieted. If an input does not activate the output layer enough, its information is boosted. Figure 1.

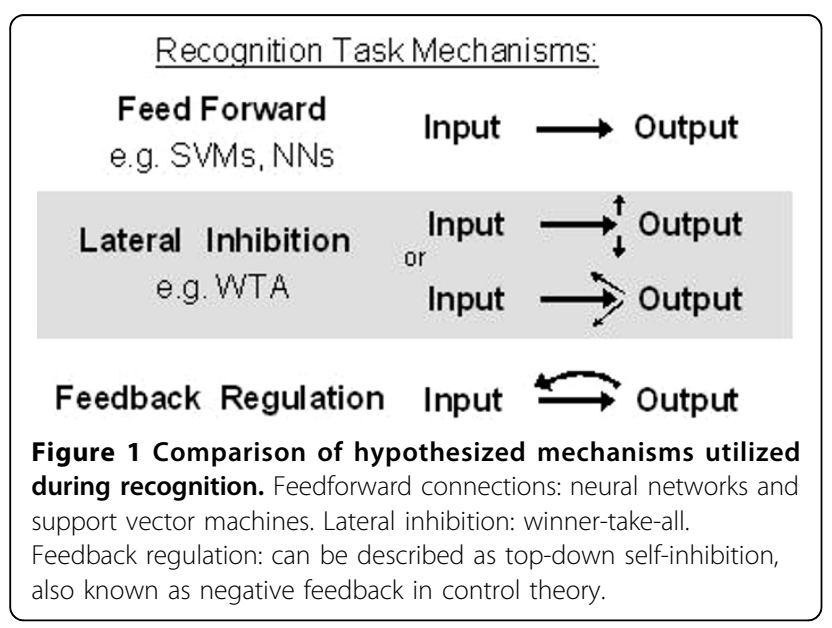

Correspondence: achler@gmail.com

Computer Science/Neuroscience, University of Illinois at Urbana-Champaign, Urbana, IL 61801, USA
Regulatory feedback networks that conserve information display unparalleled performance with simultaneous patterns. Figure 2 compares performance of various recognition mechanisms, presented with simultaneous patterns.

Such regulation offers an explanation to why salience is an integral part of recognition and the configuration

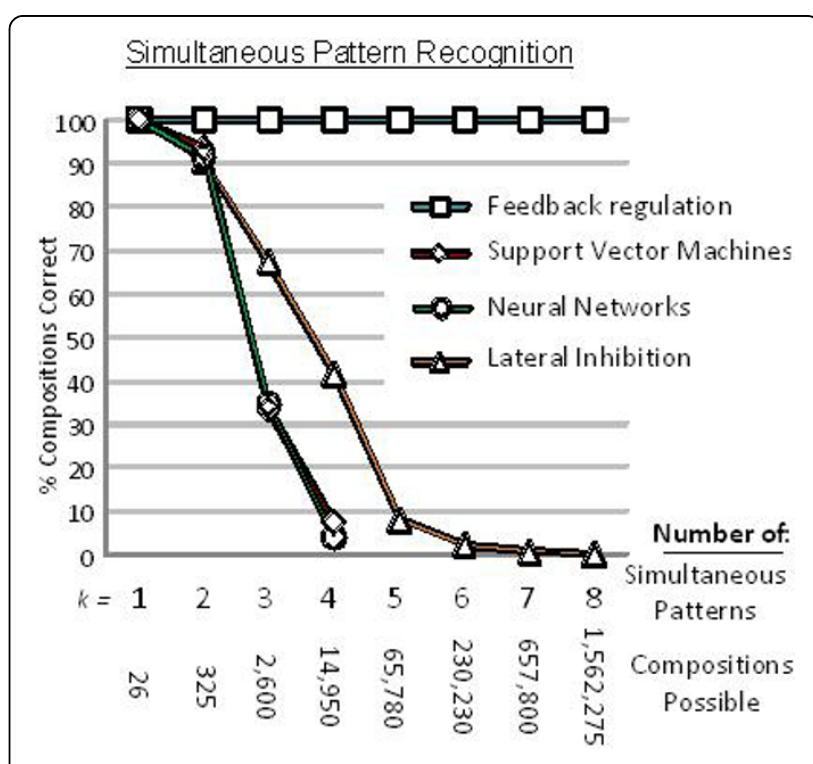

Figure 2 Simultaneous Pattern Recognition Test. The different recognition mechanisms are tested on simultaneous patterns. Such patterns are generated by combining multiple leaned patterns together and adding overlapping features. $k$ represents the number of patterns combined simultaneously, below $k$ is the number of compositions possible. 26 single patterns $(k=1)$ and pattern mixes of up to 8 simultaneously $(k=2 . .8$ ) are presented to networks that were trained on the single patterns. The vertical axis indicates the \% of combinations where the top $\mathrm{k}$ most-active nodes corresponded with the test pattern mix. Only feedback regulation inherently recognizes simultaneous patterns without training on them. 
required offers an explanation to how it is generated from a neural perspective.

Thus it is argued that feedback regulation and conservation of information are essential in enabling the brain to process simulations patterns.

Published: 20 July 2010

doi:10.1186/1471-2202-11-S1-P54

Cite this article as: Achler: Evaluating the role of feedback regulation in recognition processing. BMC Neuroscience 2010 11(Suppl 1):P54.

Submit your next manuscript to BioMed Central and take full advantage of:

- Convenient online submission

- Thorough peer review

- No space constraints or color figure charges

- Immediate publication on acceptance

- Inclusion in PubMed, CAS, Scopus and Google Scholar

- Research which is freely available for redistribution

Submit your manuscript at www.biomedcentral.com/submit 